\title{
Pesquisa qualitativa em contabilidade: um panorama de sua evolução no congresso ANPCONT à luz da literatura internacional
}

\author{
Qualitative research in accounting: an overview of its evolution in the ANPCONT congress \\ according international literature
}

\section{Investigación cualitativa en contabilidad: un panorama de su evolución en el congreso ANPCONT según la literatura internacional}

\author{
Rodrigo Carlos Marques Pereira \\ Doutorando em Ciências Contábeis na Universidade Federal do Rio de Janeiro - PPGCC (UFRJ) \\ Professor do Departamento de Ciências Contábeis e Finanças da Universidade Federal Rural do Rio de \\ Janeiro - DCCF (UFRRJ) \\ Endereço: Av. Pasteur, 250. Sala 250. FACC/UFRJ. Urca \\ CEP: 22.290-240 - Rio de Janeiro/RJ - Brasil \\ E-mail: rodrigocmp@gmail.com \\ Telefone: (21) 39385117

\section{Fabrícia de Farias da Silva Constantino} \\ Doutoranda em Ciências Contábeis na Universidade Federal do Rio de Janeiro - PPGCC (UFRJ) \\ Professora do Departamento de Ciências Contábeis e Finanças da Universidade Federal Rural do Rio de \\ Janeiro - DCCF (UFRRJ) \\ Endereço: Av. Pasteur, 250. Sala 250. FACC/UFRJ. Urca \\ CEP: 22.290-240 - Rio de Janeiro/RJ - Brasil \\ E-mail: fabriciadefarias@gmail.com \\ Telefone: (21) 39385117
}

\section{Fernanda Filgueiras Sauerbronn}

Doutora em Administração na Fundação Getúlio Vargas (FGV)

Professora do Programa de Pós-Graduação em Ciências Contábeis da Universidade Federal do Rio de Janeiro - PPGCC (UFRJ)

Endereço: Av. Pasteur, 250. Sala 250. FACC/UFRJ. Urca

CEP: 22.290-240 - Rio de Janeiro/RJ - Brasil

E-mail: fernanda.sauerbronn@gmail.com

Telefone: (21) 39385117

\section{Marcelo Alvaro da Silva Macedo}

Doutor em Engenharia de Produção na Universidade Federal do Rio de Janeiro-COPPE (UFRJ) com PósDoutorado em Controladoria e Contabilidade pela FEA (USP)

Professor do Programa de Pós-Graduação em Ciências Contábeis da Universidade Federal do Rio de Janeiro - PPGCC (UFRJ)

Endereço: Av. Pasteur, 250. Sala 250. FACC/UFRJ. Urca

CEP: 22.290-240 - Rio de Janeiro/RJ - Brasil

E-mail: malvaro.facc.ufrj@gmail.com

Telefone: (21) 39385117

Artigo recebido em 10/05/2019. Revisado por pares em 14/12/2019. Reformulado em 06/03/2020. Recomendado para publicação em 30/03/2020 por Carlos Eduardo Facin Lavarda (Editor-Chefe). Publicado em 24/04/2020. 


\title{
Resumo
}

O objetivo principal do estudo foi analisar a associação entre metodologias de pesquisa qualitativa e sua utilização nos artigos do Congresso ANPCONT entre 2007 a 2016, de forma a verificar quais são os métodos adotados pelos pesquisadores contábeis brasileiros. Na análise preliminar de 949 artigos, 325 empregaram estratégias qualitativas e foram categorizados em termos de áreas temáticas, instituições de origem, abordagens, estratégias e técnicas de coleta de dados. O protocolo metodológico foi estruturado em três etapas: análise de conteúdo, análise de correspondência e, por fim, de homogeneidade. Os resultados apontam a área CCG associada à estratégia de estudo de caso e as áreas EPC, CUE e MFC associadas às pesquisas documental e bibliográfica, mostrando certo interesse dos pesquisadores em desenvolver análises qualitativas nos fenômenos contábeis. Igualmente, o mapeamento apresentado revela o potencial de avanço dos estudos qualitativos no Brasil, considerando diferentes correntes epistemológicas, em alinhamento à literatura internacional de contabilidade.

Palavras-chave: Comunicação Científica; Mapeamento Metodológico; Pesquisa Qualitativa; Contabilidade

\begin{abstract}
The study main objective was to analyze the association between qualitative research methodologies and their usage in ANPCONT Congress articles from 2007 to 2016, to therefore verify which the methods Brazilian accounting researchers undertake. In the preliminary analysis of 949 papers, 325 used qualitative strategies and were categorized in term of thematic areas, institutional affiliation, approaches, strategies and data collection techniques. The methodological protocol was structured in three stages content analysis, correspondence analysis and then homogeneity. The results point to the CCG area associated to the case study strategy and the EPC, CUE and MFC areas associated with documentary and bibliographical research, showing some interest concern of the researchers to develop qualitative analyzes to the accounting phenomena. Likewise, the mapping presented reveals a potential to the advancement of qualitative studies in Brazil, considering different epistemological approaches, aligned with the international accounting literature.
\end{abstract}

Keywords: Scientific Communication; Methodological Mapping; Qualitative research; Accounting

\section{Resumen}

El objetivo principal del estudio fue analizar la asociación entre las metodologías de investigación cualitativa y su utilización en los artículos del Congreso ANPCONT entre 2007 y 2016, con el fin de verificar cuáles son los métodos adoptados por los investigadores contables brasileños. En el análisis preliminar de 949 artículos, 325 utilizaron estrategias cualitativas y se clasificaron en términos de áreas temáticas, instituciones de origen, enfoques, estrategias y técnicas de recopilación de datos. El protocolo metodológico se estructura en tres etapas: análisis de contenido, análisis de correspondencia y, finalmente, homogeneidad. Los resultados indican al área CCG asociada con la estrategia de estudio de caso y las áreas EPC, CUE y MFC asociadas a la investigación documental y bibliográfica, mostrando cierto interés por parte de los investigadores en el desarrollo de análisis cualitativos de fenómenos contables. Asimismo, el mapeo presentado revela el potencial para avanzar en estudios cualitativos en Brasil, considerando diferentes tendencias epistemológicas, en línea con la literatura internacional de contabilidad.

Palabras clave: Comunicación científica; Mapeo metodológico; Investigación cualitativa; Contabilidad 


\section{Introdução}

A área de ciências contábeis no Brasil, enquanto campo de conhecimento científico, pode ser considerada jovem. A consolidação da área, em grande parte, revela-se em virtude do crescimento do número de programas de pós-graduação stricto sensu na última década, com consequente aumento da produção científica. Assim, a produção desenvolvida no âmbito dos programas decorre da finalização de dissertações e teses que, muitas vezes, se convertem inicialmente em artigos para eventos e periódicos da área.

Um importante estágio no caminho do processo de construção de conhecimento e, consequentemente de produções científicas é a sua apresentação em eventos científicos. Segundo Kuhn (1962), um evento científico é um espaço amplo de comunicação científica por ser um elemento estruturante de uma comunidade, no qual os indivíduos iniciados naquela ciência constroem os limites de um objeto de estudo, mesmo que a partir de pontos de vista incompatíveis. Portanto, a quantidade de trabalhos publicados em um evento científico tende a ser fundamentalmente maior do que em revistas, por se tratar de uma etapa inicial que busca a discussão entre pesquisadores, e acaba por refletir a real intenção de produção de uma comunidade, sem que a mesma tenha passado pelo filtro de revisores e editores de revista, sendo este destino, publicação em revista, uma etapa final para trabalhos mais consolidados.

Em contabilidade, revisores e editores, por muitas vezes, podem vir a dar preferência por objetos de pesquisa e abordagens metodológicas mais afeitas ao mainstream da área (BAKER; BETTER, 1997, p. 299). Ao mesmo tempo, conforme apontam Lee e Humphrey (2006), Parker (2008) e Vaivio (2008), há na comunidade internacional uma demanda crescente por espaço para o desenvolvimento de pesquisas com abordagem qualitativa em Contabilidade, bem como o interesse em levantamentos que permitam aos pesquisadores vislumbrar lacunas para utilização de diversas estratégias de pesquisa e métodos de coleta e análise de dados. A convocação a favor da pesquisa qualitativa, realizada pelos pesquisadores internacionais de contabilidade a partir do início do século XXI (ANNISETTE; COOPER; GENDRON, 2017; HOQUE et al., 2017), tornase ainda mais relevante se considerar-se que em diversos campos do conhecimento há um avanço "neoconservador" que tenta regular e controlar o que venha a ser "boa ciência" (DENZIN; GIARDINA, 2006).

Diante deste cenário, considera-se na presente pesquisa que as publicações em eventos científicos sejam mais amplas e apresentem um potencial de denotar as inúmeras possibilidades de desenvolvimento de conhecimento, mesmo que as mesmas não tenham alcançado o produto mais valioso da comunicação científica, ou seja, a publicação em revistas científicas de alto impacto. Dentre os eventos que têm como objetivo compartilhar as pesquisas na área de Contabilidade, destaca-se o congresso organizado pela Associação Nacional de Programas de PósGraduação em Ciências Contábeis (ANPCONT). Devido à vinculação e ao interesse institucional dos programas, o Congresso ANPCONT tem o potencial de tornar-se naturalmente o destino de parcela significativa da produção científica desenvolvida no âmbito dos programas de mestrado e doutorado.

Com a crescente quantidade de artigos produzidos, observa-se uma preocupação de alguns pesquisadores quanto aos aspectos metodológicos utilizados nas pesquisas, principalmente em função da pesquisa contábil estar fortemente associada ao paradigma dominante positivista, funcionalista e quantitativo (LOURENÇO; SAUERBRONN, 2016; NASCIMENTO; JUNQUEIRA; MARTINS, 2010; RODRIGUES et al., 2011; THEÓPHILO; IUDÍCIBUS, 2009), em associação às abordagens teóricas alinhadas à economia neoclássica (IUDÍCIBUS; BUEREN; SANTOS, 2016).

Em contraposição a esse cenário nacional, Denzin e Linconl (2006, p.17) ressaltam que a pesquisa qualitativa, enquanto campo de estudo específico, abrange ampla variedade de correntes ontológicas, epistemológicas e metodológicas que "emergem na esperança de sempre conseguirem 
compreender melhor um fenômeno". Nesse sentido, o campo da pesquisa qualitativa, se constituiu, no início dos anos 1970, a partir de um movimento que incorporou múltiplas formulações paradigmáticas e que possui seus próprios periódicos científicos, associações, conferências, cursos e carreiras.

Tendo em vista as múltiplas estratégias de adoção da pesquisa qualitativa, é importante reconhecer suas possibilidades nas diversas áreas da contabilidade no Brasil. O Congresso ANPCONT foi escolhido por sua característica representativa da comunidade acadêmica em Ciências Contábeis, o mesmo está dividido nas seguintes áreas temáticas desde a sua criação em 2007: Controladoria e Contabilidade Gerencial (CCG); Contabilidade para Usuários Externos (CUE); Mercado Financeiro, de Crédito e de Capitais (MFC); Educação e Pesquisa em Contabilidade (EPC), incorporando mais recentemente a área de Contabilidade Pública e Terceiro Setor (CTP). Diante desse contexto, de múltiplas estratégias qualitativas e de ampla variedade temática na contabilidade, o presente estudo procura responder a seguinte questão de pesquisa: como as estratégias de pesquisa qualitativa estão associadas aos métodos de coletas de pesquisas publicadas nas áreas temáticas do Congresso ANPCONT?

Nesse sentido, o objetivo geral do artigo é analisar a associação entre as metodologias de pesquisa qualitativa utilizadas nos artigos apresentados, seus métodos de coleta de dados e as áreas temáticas do Congresso ANPCONT, nos dez primeiros anos de existência do evento, com a intenção de verificar quais os métodos apontados na literatura que são utilizados pela pesquisa contábil nacional. A partir de uma análise geral preliminar de 949 trabalhos publicados no evento, entre os anos de 2007 a 2016, foram considerados na análise específica os 325 artigos que empregaram estratégias qualitativas.

Detalhadamente, a análise empreendida procurou: (i) categorizar as metodologias de pesquisa qualitativa de acordo com a classificação proposta pelos principais autores, por meio da análise de conteúdo; (ii) verificar a associação entre as abordagens da pesquisa (qualitativa e quantitativa) com as áreas temáticas do Congresso ; (iii) verificar associações entre áreas temáticas da ANPCONT, instituições de ensino, abordagens, estratégias de pesquisa qualitativa e métodos de coleta de dados por meio da análise de correspondência simples (ANACOR) e múltipla (ACM) e análise de homogeneidade (HOMALS), e; (iv) apontar as lacunas na utilização efetiva das técnicas de pesquisa qualitativa contábil em âmbito nacional em comparação à diversidade de possibilidades apontadas na literatura internacional.

O estudo se justifica por apresentar uma evolução a estudos anteriores que, por meio de pesquisas bibliográficas e bibliométricas caracterizaram a pesquisa científica em contabilidade no Brasil em diferentes eventos e revistas, deixando uma lacuna na realização de estudos que contemplem as dez primeiras edições do evento da ANPCONT, bem como suas diversas áreas temáticas (BENETTI; REGINATO, 2007; SPESSATTO; BEZERRA, 2008; MENDONÇA NETO; RICCIO; SAKATA, 2009; THEÓPHILO; IUDÍCIBUS, 2009); MACHADO et al., 2011; PAULA et al., 2012; MATOS et al., 2012; SANTOS; CARLIN, 2012; COSENZA et al., 2016), e assim evidencia uma nova perspectiva sobre a produção científica sobre o tema analisado.

Espera-se, a partir dessas dimensões de análise, contribuir para uma melhor compreensão das escolhas metodológicas realizadas pela comunidade científica da área de contabilidade e traçar considerações acerca do potencial de avanço dos métodos qualitativos nas pesquisas no Brasil, considerando-se as lacunas frente à literatura internacional contábil.

$\mathrm{O}$ artigo inicia com a introdução, que apresenta o tema, o problema de pesquisa, os objetivos e a justificativa, na seção 2 é apresentada a fundamentação teórica, com os temas principais da pesquisa em contabilidade no contexto internacional e nacional, estudos anteriores e como o presente artigo avança em relação aos mesmos. Na seção 3, a metodologia apresenta o tipo da pesquisa e o método usado para análise, que está na seção 4 com apresentação dos resultados. As considerações finais estão presentes na seção 5. 
Rodrigo Carlos Marques Pereira, Fabrícia de Farias da Silva Constantino, Fernanda Filgueiras Sauerbronn, Marcelo Alvaro da Silva Macedo

\section{Fundamentação Teórica}

\subsection{Natureza do conhecimento e escolhas metodológicas em contabilidade}

Diferentes autores abordam as características metodológicas das pesquisas em contabilidade no Brasil. O espaço científico, tendo em vista o conhecimento de uma forma ampla, é um campo dinâmico sujeito à articulação de diferentes polos ou instâncias (MARTINS; THEÓPHILO, 2009). Assim, percebe-se que as escolhas metodológicas são condicionadas pelas abordagens de pesquisa em contabilidade e seus desdobramentos em função de temas e interesses a serem trabalhados, cuja diferenciação está na forma de observar o objeto de pesquisa e tentar responder a problemática de acordo com essa visão (DIAS FILHO; MACHADO, 2008). Como abordagem central, a pesquisa positiva tem o objetivo de explicar e predizer para a prática, no sentido de encontrar e apresentar seus motivos e prever fenômenos que ainda não foram observados e nem sistematizados, em contraposição à metodologia normativa, cujo objetivo era de apresentar prescrições. Nesse sentido, há na área uma escolha epistemológica relacionada à valorização de um tipo de conhecimento da contabilidade "positiva", por estar centrado nas observações da realidade e testes de hipóteses, numa postura reativa e não prescritiva (WATTS; ZIMMERMAN, 1986).

É a centralização da pesquisa no problema, e a natureza do conhecimento considerado válido e relevante, que vai fornecer indícios sobre qual abordagem deve ser utilizada (LAVILLE; DIONNE, 1999). De acordo com Vaivio (2008), uma conceituação e uma orientação teórica clara a priori, são necessárias para definir a forma de observação empírica, mas esta não deve ser sacrificada em nome de um enfoque teórico prévio. Cabe então o reconhecimento das possibilidades em termos de abordagem ao problema de pesquisa que, segundo Raupp e Beuren (2003), pode ser quantitativa ou qualitativa, em que a pesquisa quantitativa tenta compreender o comportamento geral dos acontecimentos de uma forma mais superficial, enquanto a pesquisa qualitativa se aprofunda no fenômeno a ser estudado em função da complexidade do problema e do comportamento individual dos indivíduos. Isso corrobora a visão de Richardson (1999), na qual são os problemas de pesquisa que demandam uma metodologia quantitativa para o seu entendimento, enquanto há outros que necessitam da metodologia qualitativa. Em termos de desdobramentos epistêmico-metodológicos, a posição de Dowd (2004) é pragmática: deve-se usar o que parece funcionar para o problema em mãos, e evitar o dogmatismo excessivo, já que metodologia não é uma ciência exata.

Portanto, no presente estudo reconhece-se que a pesquisa qualitativa pode ser diferenciada da quantitativa, pois os pesquisadores qualitativos ressaltam a natureza da realidade, a íntima relação entre o pesquisador e o que é estudado, e as limitações situacionais que influenciam a investigação; enquanto que os quantitativos enfatizam o ato de medir e de analisar as relações causais entre variáveis, e não processos (DENZIN; LINCOLN, 2006).

Apresenta-se, então, o que Vaivio (2008) denomina de dilema (profundidade versus amplitude), em que é importante construir uma evidência empírica confiável e válida obtida profissionalmente com coleta de dados meticulosa. Segundo o autor, geralmente, quanto mais tempo o pesquisador passa no contexto estudado, menos vulnerável o estudo será a fatores que comprometem sua confiabilidade e validade. No entanto, é aconselhável moderação, distância apropriada do contexto de estudo, independência da natureza do estudo. Isso corrobora a visão de Denzin e Lincoln (2006) na qual a pesquisa qualitativa consiste em um conjunto de práticas materiais e interpretativas que dão visibilidade ao mundo, com uma abordagem naturalista, seus pesquisadores estudam as coisas em seus cenários naturais, tentando entender os fenômenos em termos dos significados que as pessoas a eles conferem.

Há que se reconhecer, ainda, a possibilidade de integração das abordagens quantitativa e qualitativa em um mesmo estudo, chamado método misto (CRESWELL, 1999). Modell (2010) 
apresenta suas inquietações quanto ao desenvolvimento de métodos mistos na pesquisa contábil, como aquelas voltadas aos aspectos sociais, políticos e institucionais da contabilidade e controle gerencial, já que as demandas de entrada e entendimento no campo vão além das respostas trazidas pelos métodos quantitativos nesta área. Conforme o autor, a pesquisa de métodos mistos pode ajudar os pesquisadores a reduzir o hiato entre a abordagem funcionalista dominante (mainstream) e a alternativa com perspectivas interpretativa e crítica.

\subsection{Pesquisa qualitativa em Contabilidade}

O contexto da pesquisa contábil ainda apresenta uma visão dominante do que venha a ser uma "boa e rigorosa pesquisa" na área, num paradigma positivista, e com ênfase em aspectos econômicos (teoria neoclássica) e de forma unitária, características da pesquisa norte-americana (PARKER, 2008). Entretanto, Lee e Humphrey (2006) argumentaram que o aparente viés quantitativo da contabilidade faz equivocadamente com que pareça que a área não fazia pesquisas qualitativas. Segundo os autores, a pesquisa em contabilidade e finanças continuavam a ser predominantemente quantitativa, assim como a pesquisa acadêmica nos Estados Unidos; enquanto no Reino Unido os trabalhos em contabilidade se desenvolviam com ecletismo surpreendente, incluindo pesquisas qualitativas.

O desenvolvimento da pesquisa qualitativa aumentou por ser uma alternativa de estrutura de pesquisa além dos relatórios financeiros (LEE; HUMPHREY, 2006) e isso leva em conta as publicações e conferências da área, inclusive com estudos de caso (SCAPENS, 2004). Esse tipo de pesquisa pode envolver o estudo do uso e coleta de uma variedade de materiais empíricos que descrevem momentos e significados rotineiros e problemáticos na vida dos indivíduos (DENZIN; LINCOLN, 2006).

Várias interações entre a teoria e os dados são normalmente necessárias, e um ponto importante na pesquisa qualitativa é a triangulação entre diferentes fontes de materiais empíricos de forma a prover dados que aumentem a confiabilidade (VAIVIO, 2008). Nesse sentido, Lee e Humphrey (2006) apontaram como métodos qualitativos mais utilizados na área contábil: entrevistas semiestruturadas em conjunto com pesquisa documental e observação quando utilizada a abordagem de estudo de caso; observação participante, quando informações relevantes não podem ser reveladas por outros métodos e pode ser suplementar na utilização das entrevistas; pesquisa documental, utilizada na pesquisa histórica em Contabilidade e na narrativa do desenvolvimento da profissão contábil. Adicionalmente, para os autores, é na análise das entrevistas, dada sua popularização como forma de coleta, destacam-se as formas variadas de analisar esses achados, inclusive com utilização de softwares.

Uma importante contribuição para o adequado entendimento da pesquisa contábil qualitativa é apresentada por Hoque et al. (2017). Esses pesquisadores apresentam, em um volume de 541 páginas, a consolidação de diferentes paradigmas, estratégias metodológicas, métodos de coleta e tópicos relevantes aos pesquisadores qualitativos em contabilidade (ver Quadro 1). Com a organização desse volume, os autores trazem à tona a consolidação de uma vasta gama de pesquisa qualitativas realizadas e publicadas internacionalmente, como uma clara demonstração do amadurecimento dessas abordagens na área contábil.

Consequentemente, percebe-se que os pesquisadores de contabilidade no Brasil possuem uma diversidade, tanto epistemológica, quanto metodológica, para desenvolverem seus estudos, em alinhamento à pesquisa qualificada internacional. Conforme Vaivio (2008), tal característica pode ocorrer também em termos de técnicas de coleta e tratamento de dados, visando ao estudo de materiais empíricos significativos, de forma a ter mais subsídios na interpretação de um fenômeno contábil pensado a partir de outras epistemologias. 
Rodrigo Carlos Marques Pereira, Fabrícia de Farias da Silva Constantino, Fernanda Filgueiras Sauerbronn, Marcelo Alvaro da Silva Macedo

\begin{tabular}{|c|c|c|c|}
\hline Paradigmas & $\begin{array}{c}\text { Estratégias } \\
\text { Metodológicas }\end{array}$ & Coleta e Tratamento & Tópicos Relevantes \\
\hline $\begin{array}{l}\text { Construção Social da } \\
\text { Realidade }\end{array}$ & $\begin{array}{l}\text { Etnografia e } \\
\text { Etnométodos }\end{array}$ & Métodos Mistos & $\begin{array}{l}\text { Reflexões sobre uso de } \\
\text { estudo de caso }\end{array}$ \\
\hline Pesquisa Interpretativa & Estudo de Caso & Entrevistas & Ética na etnografia \\
\hline Estudos Críticos & Narrativas & Observação Participante & Ética e pesquisa de campo \\
\hline Historiografia & História Oral & Grupos Focais & $\begin{array}{c}\text { Condução da pesquisa no } \\
\text { campo }\end{array}$ \\
\hline Grounded Theory & Autoetnografia & Documentos & Reflexividade \\
\hline Estudos Visuais & Pesquisa Ação & Organização dos Dados & \\
\hline \multirow[t]{3}{*}{ Estudos Apreciativos } & Pesquisa Intervencionista & Uso de Software & \\
\hline & Análise de Conteúdo & $\begin{array}{l}\text { Credibilidade e } \\
\text { Autenticidade }\end{array}$ & \\
\hline & Análise de Discurso & & \\
\hline
\end{tabular}

Fonte: elaborado a partir de (Hoque et al., 2017)

Assim se acredita que pesquisadores de contabilidade são desafiados a continuar buscando o novo, conciliando a dupla tarefa de defender sua tradição e ao mesmo tempo continuar a construir as suas contribuições para a distintiva literatura contábil, mantendo um compromisso com a compreensão dos fenômenos específicos da área (PARKER, 2008).

\subsection{Panorama da pesquisa contábil no Brasil}

Dias Filho e Machado (2008, p.30) percebem que "a pesquisa em contabilidade tem procurado instrumentalizar-se cada vez mais para fornecer explicações e predições para a prática contábil (...) e que diversas questões passaram a ser examinadas com maior rigor científico". A pesquisa qualitativa vem ganhando mais espaço ao longo do tempo na área de contabilidade (RODRIGUES et al., 2011) mesmo com a prevalência de estudos quantitativos. Esta seria uma forma, segundo os autores, de compreensão dos fenômenos organizacionais em profundidade, cujas nuances não podem ser interpretadas somente com os métodos quantitativos, ou ainda com uma integração das duas abordagens sobre o problema. No Brasil, a pesquisa na área cresce e alguns estudos foram feitos no sentido de entender esse desenvolvimento, principalmente quanto às escolhas epistemológicas e metodológicas realizadas no campo.

Martins (2005) apresenta uma discussão que destaca o normativismo e o positivismo como os aspectos principais de debate; a partir da década de 70, o domínio da estatística e da matemática para comprovar ou não hipóteses passou a ser tão importante quanto o conhecimento da contabilidade, e virou símbolo de pesquisa científica na área. Esse perfil de desenvolvimento dos estudos levou a um quadro monoparadigmático centrado, quase que exclusivamente, na teoria neoclássica para explicar fenômenos contábeis (FREZATTI; NASCIMENTO; JUNQUEIRA, 2009), podendo ser caracterizado pela existência de uma falsa dicotomia entre as abordagens qualitativa e quantitativa, bem como pela opção por uma abordagem monometodológica que caracterizaria uma boa pesquisa (VIEIRA, 2004).

Diante desse cenário, Martins (2005) propõe, então, uma convivência mais produtiva em que se pudesse aceitar que alguns autores pensam, criam, mas não conseguem comprovar, enquanto outros têm maior habilidade e capacidade para as verificações empíricas, porém não são bons como criadores. Segundo essa proposição nasceria um círculo virtuoso, em que os usuários da contabilidade apresentariam o que realmente precisam e querem, os normativistas produziriam essas respostas com sua criatividade e os positivistas apresentariam pesquisas e provas para testálas, gerando novas demandas para os normativistas.

Portanto, esta pesquisa reconhece que diferentes métodos podem ser utilizados para um mesmo objeto de estudo com a finalidade de dar diferentes visões e aumentar o conhecimento 
sobre problemas contábeis e tratar de forma diferenciada o que deve ser tratado desta maneira, sem misturar e se equivocar com os conceitos (VIEIRA, 2004).

Nesse sentido, alinha-se a construção do problema de pesquisa ao argumento de Lourenço e Sauerbronn (2016) no qual a pesquisa contábil brasileira poderia pensar em diferentes caminhos epistemológicos e metodológicos para alcançar pluralismo, coexistência de perspectivas e geração de outros conhecimentos. Para as autoras, há uma inadequada representatividade da pesquisa crítica e interpretativa e, no Brasil se tende a utilizar o monoparadigma econômico. As autoras concluem que existe espaço para que se amplie o entendimento de que a contabilidade está entrelaçada a processos sociais, culturais e políticos.

Ao alinhar a argumentação aos pesquisadores europeus, é reconhecido que as abordagens alternativas, especificamente em contabilidade gerencial, oferecem contribuições para o desenvolvimento da contabilidade. Tendo em vista a complexidade dos fenômenos contábeis e organizacionais, determinados problemas serão insuficientemente explorados, se forem tratados sob um único ponto de vista, logo, outras abordagens serão mais aptas para interpretação da realidade.

Neste contexto, o Quadro 2 apresenta uma síntese de estudos que tratam do perfil da produção acadêmica na área de Contabilidade no Brasil, com pesquisas bibliográficas e bibliométricas que consideraram artigos, teses ou dissertações, publicados entre 2007 e 2016.

Quadro 2 - Estudos anteriores

\begin{tabular}{|c|c|c|c|}
\hline Autores & Base de análise & Metodologia & Principais Achados \\
\hline $\begin{array}{l}\text { Benetti e } \\
\text { Reginato } \\
(2007)\end{array}$ & $\begin{array}{l}250 \quad \text { artigos } \\
\text { publicados nos anais } \\
\text { do } 5^{\circ} \text { e } 6^{\circ} \text { congressos } \\
\text { USP } \\
\text { controladoria de } \\
\text { contabilidade. }\end{array}$ & $\begin{array}{l}\text { Análise de conteúdo dos } \\
\text { artigos quanto às } \\
\text { abordagens, e a associação } \\
\text { entre as cinco áreas de } \\
\text { concentração do evento } \\
\text { com a aplicação da } \\
\text { ANACOR. }\end{array}$ & $\begin{array}{l}\text { Há associação significativa entre a } \\
\text { abordagem quantitativa à área de Mercado de } \\
\text { Capitais, entre a abordagem qualitativa à área } \\
\text { de Temas Emergentes e entre a abordagem } \\
\text { mista e à área EPC. A amostra não revelou } \\
\text { associação das áreas CUE e CCG a nenhuma } \\
\text { das dimensões. }\end{array}$ \\
\hline $\begin{array}{l}\text { Spessatto e } \\
\text { Bezerra } \\
(2008)\end{array}$ & $\begin{array}{l}\text { Sites dos PPGCC } \\
\text { stricto sensu: USP, } \\
\text { UNB e FURB para o } \\
\text { período de } 1998 \text { a } \\
\text { 2007. Constituiu em } \\
\text { análise de } 450 \\
\text { resumos. }\end{array}$ & \begin{tabular}{ll} 
Pesquisa & \multicolumn{2}{c}{ descritiva, } \\
bibliográfica e qualitativa \\
com classificação da \\
pesquisa em positiva e \\
normativa baseada na \\
intenção explícita do \\
pesquisador.
\end{tabular} & $\begin{array}{l}\text { Utilização de } 69,11 \% \text { da abordagem positiva } \\
\text { e } 30,89 \% \text { da abordagem normativa. } \\
\text { Pesquisadores da área contábil estão } \\
\text { explorando novas formas de se fazer pesquisa } \\
\text { e corroborando para que a contabilidade } \\
\text { atinja um status mais científico. }\end{array}$ \\
\hline $\begin{array}{l}\text { Mendonça } \\
\text { Neto, } \\
\text { Riccio e } \\
\text { Sakata } \\
(2009)\end{array}$ & $\begin{array}{l}\text { Trabalhos } \\
\text { contabilidade } \\
\text { apresentados } \\
\text { ENANPADs nos } \\
1996 \text { a 2005. } \\
4.582 \text { títulos, dos } \\
\text { quais } 405 \text { estão } \\
\text { relacionados com a } \\
\text { contabilidade. }\end{array}$ & $\begin{array}{l}\text { Análise dos resumos dos } \\
\text { trabalhos e classificação dos } \\
\text { selecionados em positivos e } \\
\text { normativos com análise } \\
\text { quantitativa utilizando o } \\
\text { modelo de Lotka. }\end{array}$ & $\begin{array}{l}\text { Predominância da pesquisa positiva. Baixa } \\
\text { produtividade dos pesquisadores, constatada } \\
\text { por meio dos coeficientes } c \text { da Lei de Lotka } \\
\text { generalizada, que resultou em: pesquisas da } \\
\text { FEA-USP respondem individualmente por } \\
\text { parte importante da produção em } \\
\text { contabilidade, merecem destaque também: o } \\
\text { programa conjunto } \\
\text { UNB/UFPB/UFPE/UFRN e FUCAPE. }\end{array}$ \\
\hline $\begin{array}{l}\text { Theóphilo } \\
\text { e Iudícibus } \\
\text { (2009) }\end{array}$ & $\begin{array}{l}\text { Dissertações, teses e } \\
\text { artigos de congresso } \\
\text { e de periódico em } \\
\text { Ciências Contábeis } \\
\text { entre } 1994 \text { e } 2003 \text {. }\end{array}$ & $\begin{array}{l}\text { Categorização de } 238 \\
\text { trabalhos de uma população } \\
\text { de } 1.079 \text {, por meio da } \\
\text { análise de conteúdo. }\end{array}$ & $\begin{array}{l}57 \% \text { dos trabalhos foram considerados } \\
\text { estudos teórico-empíricos } \\
\text { predominância de pesquisa } \\
\text { levantamento e estudo de comental, } \\
\text { categorizados } \\
\text { metodológica positivista. }\end{array}$ \\
\hline
\end{tabular}


Rodrigo Carlos Marques Pereira, Fabrícia de Farias da Silva Constantino, Fernanda Filgueiras Sauerbronn, Marcelo Alvaro da Silva Macedo

\begin{tabular}{|c|c|c|c|}
\hline Autores & Base de análise & Metodologia & Principais Achados \\
\hline $\begin{array}{l}\text { Machado et } \\
\text { al. (2011) }\end{array}$ & $\begin{array}{lr}86 \quad \text { manuscritos } \\
\text { veiculados em } & 10 \\
\text { edições } & \text { do } \\
\text { Congresso USP } & \text { de } \\
\text { Controladoria } & \text { e } \\
\text { Contabilidade } \\
\text { (2001-2010), na área } \\
\text { temática de EPC. }\end{array}$ & $\begin{array}{l}\text { Estudo descritivo, de } \\
\text { natureza documental e } \\
\text { longitudinal. Investigação } \\
\text { da produção científica da } \\
\text { área. Classificação dos } \\
\text { estudos quanto às } \\
\text { estratégias investigativas, } \\
\text { quanto às técnicas de coleta } \\
\text { de dados, e quanto às } \\
\text { técnicas de análise de } \\
\text { dados. }\end{array}$ & $\begin{array}{l}\text { Pesquisadores da área EPC têm recorrido à } \\
\text { aplicação de questionários e abordagens } \\
\text { quantitativas para leitura dos dados, } \\
\text { predominantemente, na forma positivista, } \\
\text { com emprego de estatística descritiva como o } \\
\text { recurso mais recorrente. Apenas nos últimos } \\
\text { anos o emprego da abordagem foi } \\
\text { incrementado por técnicas de associação de } \\
\text { variáveis e inferenciais e o estabelecimento } \\
\text { de contornos metodológicos, com prejuízo } \\
\text { das necessárias vigilâncias ontológica e } \\
\text { epistemológica. }\end{array}$ \\
\hline $\begin{array}{l}\text { Paula et al., } \\
\quad(2012)\end{array}$ & $\begin{array}{lr}229 & \text { artigos } \\
\text { publicados nos anais } \\
\text { do } \\
\text { ANPCONT } \\
\text { período de } 2007 \text { a } \\
2010 .\end{array}$ & $\begin{array}{l}\text { Categorização dos trabalhos } \\
\text { quanto aos métodos de } \\
\text { pesquisa e ao foco do } \\
\text { estudo, além de citações de } \\
\text { artigos que foram } \\
\text { publicados. }\end{array}$ & $\begin{array}{l}\text { Pela análise de frequência, foram observados } \\
\text { que } 89,52 \% \text { dos artigos utilizaram métodos } \\
\text { de natureza empírica, e que cabe um destaque } \\
\text { para a área de CCG para a diversidade de } \\
\text { métodos. Dos } 229 \text { artigos, apenas } 13 \text { foram } \\
\text { citados em artigos do próprio Congresso. }\end{array}$ \\
\hline $\begin{array}{c}\text { Matos et } \\
\text { al., (2012) }\end{array}$ & $\begin{array}{l}\text { Artigos apresentados } \\
\text { no Congresso } \\
\text { ANPCONT dos anos } \\
\text { de } 2007 \text { a } 2011 . \\
\text { Total de artigos } \\
\text { analisados: } 383 \text {. }\end{array}$ & $\begin{array}{l}\text { Metodologias } \\
\text { bibliométricas } \\
\text { (Lei de Lotka) e avaliativas } \\
\text { (tipos das referências } \\
\text { utilizadas) no banco de } \\
\text { dados } \\
\begin{array}{l}\text { contendo } \\
\text { características gerais dos } \\
\text { artigos. }\end{array}\end{array}$ & $\begin{array}{l}\text { Os autores são principalmente ligados ao } \\
\text { meio acadêmico, sendo próximo a } 50 \% \text { o } \\
\text { número de doutores. Universidades que } \\
\text { possuem maior nível de publicação: USP } \\
\text { (SP), Fucape (ES) e FURB (SC). Padrão } \\
\text { estabelecido por Lotka da "elite acadêmica", } \\
\text { poucos autores contribuem com muitos } \\
\text { artigos e muitos autores contribuem com } \\
\text { poucos artigos. Número de autores por artigo } \\
\text { é crescente, uma média de } 2 \text { e } 3 \text {, logo as redes } \\
\text { de colaboração podem estar crescendo. }\end{array}$ \\
\hline $\begin{array}{l}\text { Santos e } \\
\text { Carlin } \\
(2012)\end{array}$ & $\begin{array}{l}\text { Anais } \text { dos } \\
\text { Congressos } \\
\text { ANPCONT } \\
\text { realizados nos anos } \\
\text { de } 2009 \text { e } 2010,142 \\
\text { artigos. }\end{array}$ & $\begin{array}{l}\text { Pesquisa } \begin{array}{c}\text { dedutiva, } \\
\text { descritiva, } \\
\text { quantitativa, bibliomentrical, }\end{array} \\
\text { quamental }\end{array}$ & $\begin{array}{l}\text { Houve uma concentração da produção } \\
\text { científica nas regiões sudeste e sul, e em } \\
\text { relação às áreas temáticas, na área CCG. } \\
\text { Houve indícios de formação de grupos de } \\
\text { pesquisa na maioria dos trabalhos, bem como } \\
\text { a predominância do sexo masculino na } \\
\text { produção científica. }\end{array}$ \\
\hline $\begin{array}{l}\text { Cosenza et } \\
\text { al., (2016) }\end{array}$ & $\begin{array}{l}395 \text { artigos } \\
\text { apresentados entre } \\
2007 \text { e 2014, no } \\
\text { ANPCONT, nas } \\
\text { áreas temáticas } \\
\text { CUE e CCG. }\end{array}$ & $\begin{array}{l}\text { Pesquisa exploratório- } \\
\text { descritiva com análise } \\
\text { bibliográfica e utilizando a } \\
\text { técnica de Escalonamento } \\
\text { Multidimensional. }\end{array}$ & $\begin{array}{l}\text { Os congressos possuem tradição de pesquisa } \\
\text { baseada em abordagem positiva, com } \\
\text { preponderância de métodos quantitativos. } \\
\text { Métodos com base empírica, mas que, vêm } \\
\text { cedendo lugar para métodos de estudos de } \\
\text { caso e surveys. CUE - pesquisas positivas de } \\
\text { caráter empírico, CCG - métodos e } \\
\text { paradigmas de forma mais bem distribuída, } \\
\text { mais heterogênea e variada }\end{array}$ \\
\hline
\end{tabular}

Fonte: Elaborado a partir da literatura citada.

É possível observar a partir do Quadro 2 que os estudos que realizaram levantamentos mostram-se, muitas vezes, limitados em termos de recorte temporal, ou por colocar foco em outro evento científico ou delimitar a apenas uma área temática do evento. Desse modo, percebe-se uma lacuna na realização de estudos que contemplem as diversas edições do evento da ANPCONT desde sua criação, bem como as diversas áreas de submissão.

\section{Procedimentos Metodológicos}

Este trabalho tem o objetivo de analisar a associação entre as metodologias de pesquisa qualitativa utilizadas na área contábil e as áreas temáticas do Congresso ANPCONT, verificando 
quais os métodos apontados na literatura que são utilizados pela pesquisa contábil nacional, sendo de caráter descritivo. O problema de pesquisa foi abordado por meio de método misto, combinando análise qualitativa e quantitativa, por meio da utilização de análise de conteúdo e de estatística multivariada.

A coleta dos dados foi feita por meio do acesso aos anais do Congresso ANPCONT, disponíveis nos CDs e sites das dez edições do evento. Desde a sua primeira edição este evento recebe trabalhos divididos em quatro áreas temáticas: controladoria e contabilidade gerencial (CCG); contabilidade para usuários externos (CUE); mercado financeiro, de crédito e de capitais (MFC); educação e pesquisa em contabilidade (EPC); e a partir de 2015 foi criada a quinta área temática: contabilidade aplicada ao setor público e terceiro setor (CPT).

Como o objetivo deste trabalho é apresentar um perfil das publicações ao longo de todos os anos, e a área CPT possuía apenas dois anos de existência, foi feita uma reclassificação dos artigos desta área para as áreas já existentes desde a criação do evento. Assim, o universo da pesquisa é composto pelos artigos publicados nos primeiros dez anos de existência do evento, de 2007 a 2016, em virtude da realização da pesquisa no ano de 2017 em comemoração ao aniversário de 10 anos do evento.

Para as análises preliminares (área $\mathrm{x}$ abordagem e área $\mathrm{x}$ abordagem $\mathrm{x}$ instituição) foi utilizado toda a população de 949 artigos publicados, observando em cada um deles a abordagem utilizada. Já para a análise principal da pesquisa (área x coleta x estratégia) foram selecionados os artigos que utilizaram a abordagem qualitativa, ou seja, 327 artigos, porém dois artigos de 2009 foram excluídos por apresentarem apenas o resumo, impossibilitando as classificações necessárias. Logo, a análise final foi feita com 325 artigos qualitativos.

Desta forma, a base de dados foi construída com o ano da publicação do artigo, sua respectiva área, instituição (levando em conta apenas a instituição do primeiro autor do artigo) e abordagem. Nos artigos de abordagem qualitativa e qualitativa/quantitativa foram analisadas as estratégias de pesquisa e coleta de dados, além da abordagem científica da pesquisa contábil (positiva ou normativa).

Em virtude de os artigos terem sido classificados em diferentes categorias e visando buscar uma possível associação entre elas, para o tratamento dos dados foram empregadas as técnicas de análise de correspondência (ANACOR) e análise de homogeneidade (HOMALS).

Para o tratamento quantitativo dos dados foi utilizado o software IBM SPSS Statistics, que permite apresentar todas as análises das técnicas, com a tabela de correspondência, o resultado do teste Qui-Quadrado, e o mapa perceptual com a relação das variáveis empregadas no estudo. O mapa perceptual representa, visualmente, as percepções de um indivíduo sobre objetos (categorias das variáveis) em duas ou mais dimensões, que são as suas próprias características. Sendo assim, cada objeto/categoria possui uma posição espacial no mapa perceptual que reflete a similaridade relativa a outros objetos/categorias no que se refere às dimensões do mapa (FÁVERO et al., 2009).

\section{Apresentação e Análise dos Resultados}

As análises e resultados da pesquisa se apresentam no sentido de atender aos objetivos específicos abordados na Introdução e descritos no Quadro 3.

Quadro 3 - Objetivos de pesquisa e seus procedimentos de operacionalização

\begin{tabular}{|l|l|}
\hline \multicolumn{1}{|c|}{ Objetivos } & \multicolumn{1}{c|}{ Procedimentos } \\
\hline $\begin{array}{l}\text { Categorizar as metodologias de pesquisa qualitativa } \\
\text { de acordo com a classificação proposta pelos } \\
\text { principais autores. }\end{array}$ & $\begin{array}{l}\text { Classificação das metodologias com base nos autores: } \\
\text { Richardson (1999), Denzin e Linconl (2006) e Vergara } \\
(2009) ; \text { e análise de conteúdo segundo Bardin (1977). }\end{array}$ \\
\hline $\begin{array}{l}\text { Verificar a associação entre as abordagens da } \\
\text { pesquisa (qualitativa e quantitativa) com as áreas } \\
\text { temáticas do Congresso. }\end{array}$ & $\begin{array}{l}\text { Análise de correspondência (ANACOR) e apresentação } \\
\text { visual por meio do mapa perceptual entre área e } \\
\text { abordagem. }\end{array}$ \\
\hline \multicolumn{2}{|c|}{ ISSN 2175-8069, UFSC, Florianópolis, v. 16, n. 41, p. 204-224, out./dez. 2019} \\
\hline $\begin{array}{l}\text { Rerista } \\
\text { Contabilidade }\end{array}$
\end{tabular}


Rodrigo Carlos Marques Pereira, Fabrícia de Farias da Silva Constantino, Fernanda Filgueiras Sauerbronn, Marcelo Alvaro da Silva Macedo

\begin{tabular}{|l|l|}
\hline \multicolumn{1}{|c|}{ Objetivos } & \multicolumn{1}{c|}{ Procedimentos } \\
\hline $\begin{array}{l}\text { Verificar associações entre áreas temáticas da } \\
\text { ANPCONT, instituições de ensino, abordagens, } \\
\text { estratégias de pesquisa qualitativa e métodos de } \\
\text { coleta de dados. }\end{array}$ & $\begin{array}{l}\text { Análise de correspondência simples (ANACOR) e } \\
\text { múltipla (ACM), análise de homogeneidade } \\
\text { (HOMALS) e apresentação visual por meio do mapa } \\
\text { perceptual entre área, estratégia e coleta de dados. }\end{array}$ \\
\hline $\begin{array}{l}\text { Apontar as lacunas na utilização efetiva das } \\
\text { técnicas de pesquisa qualitativa contábil em âmbito } \\
\text { nacional em comparação à diversidade de } \\
\text { possibilidades apontadas na literatura internacional. }\end{array}$ & Análise dos resultados da pesquisa. \\
\hline
\end{tabular}

Fonte: Dados da pesquisa.

\subsection{Categorização das metodologias de pesquisa}

Neste estudo as pesquisas analisadas foram categorizadas conforme apresentado na metodologia da pesquisa. A Tabela 1 apresenta a quantidade total de artigos enviados, recomendados para publicação e publicados nas edições de 2007 a 2016, assim como o perfil das publicações de acordo com as áreas aplicadas.

Tabela 1 - Caracterização Temporal dos Artigos do Congresso ANPCONT

\begin{tabular}{cccccccccccc}
\hline Ano & 2007 & 2008 & 2009 & 2010 & 2011 & 2012 & 2013 & 2014 & 2015 & 2016 & Total \\
\hline Enviados & 289 & 432 & 303 & 326 & 302 & 294 & 342 & 324 & 325 & 321 & 3258 \\
Aprovados & 49 & 48 & 107 & 81 & 102 & 101 & 119 & 100 & 118 & 141 & 1037 \\
Publicados & 47 & 47 & 105 & 81 & 101 & 97 & 118 & 98 & 118 & 137 & 949 \\
$\%$ & 16,26 & 10,88 & 34,65 & 24,85 & 33,44 & 32,99 & 34,50 & 30,25 & 36,31 & 42,68 & 29,13 \\
\hline CCG & 18 & 18 & 28 & 23 & 27 & 30 & 33 & 27 & $32(\mathbf{7})$ & $26(\mathbf{7})$ & 262 \\
CUE & 16 & 17 & 41 & 24 & 33 & 34 & 46 & 36 & $29(\mathbf{1 0})$ & $48(\mathbf{8})$ & 324 \\
MFC & 8 & 6 & 17 & 18 & 16 & 16 & 19 & 20 & 21 & 24 & 165 \\
EPC & 5 & 6 & 19 & 16 & 25 & 17 & 20 & 15 & 19 & $23(1)$ & 165 \\
CPT & - & - & - & - & - & - & - & - & $\mathbf{1 7}$ & $\mathbf{1 6}$ & 33 \\
\hline Quali & 22 & 8 & 29 & 27 & 25 & 27 & 22 & 25 & 28 & 22 & 235 \\
Quanti & 24 & 32 & 73 & 48 & 63 & 57 & 84 & 58 & 80 & 103 & 622 \\
Quali/Quanti & 1 & 7 & 3 & 6 & 13 & 13 & 12 & 15 & 10 & 12 & 92 \\
\hline
\end{tabular}

Fonte: Dados da Pesquisa.

Observa-se que o percentual de aprovação dos trabalhos vem aumentando ao longo das edições, passando de 47 artigos publicados em 2007 para 137 em 2016, totalizando 949 artigos ao longo dos dez anos de evento, em que se destaca que a área CUE foi a que apresentou maior número de trabalhos. Também em função do crescimento do evento em tamanho, com uma taxa de aprovação média de 29,13\% ao longo de todo o período, percebe-se, um aumento das pesquisas que utilizam tanto abordagem quantitativa quanto qualitativa.

A análise dos artigos foi feita pelo resumo, metodologia e introdução, por meio da análise de conteúdo que "visa obter, por procedimentos sistemáticos e objetivos de descrição do conteúdo das mensagens, indicadores que permitam a inferência de conhecimentos relativos às condições de produção/recepção de mensagens" (BARDIN, 1977, p.42).

para atingir os objetivos da pesquisa os dados foram classificados quanto à abordagem: qualitativa, quantitativa e qualitativa/quantitativa, conforme Richardson (1999); quanto à estratégia de pesquisa qualitativa: estudo de caso (EC), etnografia (ET), grounded theory (GT), método histórico $(\mathrm{MH})$, pesquisa ação (PA), levando em consideração a classificação proposta por Denzin e Linconl (2006), acrescentando bibliográfica (BI) e documental (DO), conforme Vergara (2009); quanto à coleta de dados qualitativos: entrevista (Ent), observação (Obs), documentos 
(Doc), métodos visuais (MVi), métodos de controle de dados (MCD), grupos focais (GF), além de categorias que combinavam dois ou mais tipos de coleta de dados, adaptados de Denzin e Linconl (2006).

\subsection{Associação entre áreas temáticas e abordagens de pesquisa}

Para atingir o objetivo específico de verificar a associação entre as abordagens de pesquisa com as áreas temáticas do Congresso ANPCONT, foi realizada uma análise de conteúdo de todos os artigos, e posterior análise de correspondência.

O resultado do teste qui-quadrado mostra que há associação entre as variáveis área e abordagem, sendo assim, ao nível de significância de 5\%, há indícios que apontam à rejeição de $\mathrm{H}_{0}$ de independência das variáveis, ou seja, pode ser aplicada a ANACOR.

A Tabela 2 evidencia a existência de uma quantidade maior de trabalhos nas áreas de CUE e CCG do que em MFC e EPC, em que ambas possuem quantidade próxima de trabalhos. Notase, também, que existem mais trabalhos quantitativos do que qualitativos e alguns que associam as duas abordagens. O mesmo ocorrendo em cada uma das áreas, ou seja, há maior número de trabalhos quantitativos, sendo que na área EPC a diferença é menos expressiva do que em MFC, que possui cerca de $94 \%$ de seus trabalhos quantitativos.

Tabela 2 - Tabela de Correspondência

\begin{tabular}{lcccc}
\hline ÁREA & \multicolumn{4}{c}{ ABORDAGEM } \\
\cline { 2 - 5 } & Quali & Quali/Quanti & Quanti & Active Margin \\
\hline CCG & 91 & 30 & 155 & 276 \\
CUE & 80 & 30 & 232 & 342 \\
MFC & 5 & 4 & 156 & 165 \\
EPC & 59 & 28 & 79 & 166 \\
Active Margin & 235 & 92 & 622 & 949 \\
\hline
\end{tabular}

Fonte: Dados da Pesquisa.

A Figura 1 apresenta o mapa perceptual entre as áreas e as abordagens e indica que a área CCG possui maior ligação com abordagem qualitativa, enquanto a EPC, está ligada à abordagem conjunta qualitativa/quantitativa, mostrando um avanço do aumento da frequência de utilização de métodos qualitativos nos trabalhos do Congresso ANPCONT, diferente dos resultados encontrados na pesquisa de Machado et al. (2011) que analisou os artigos do Congresso USP de Contabilidade entre 2001 a 2010.

Figura 1 - Mapa Perceptual entre Área e Abordagem

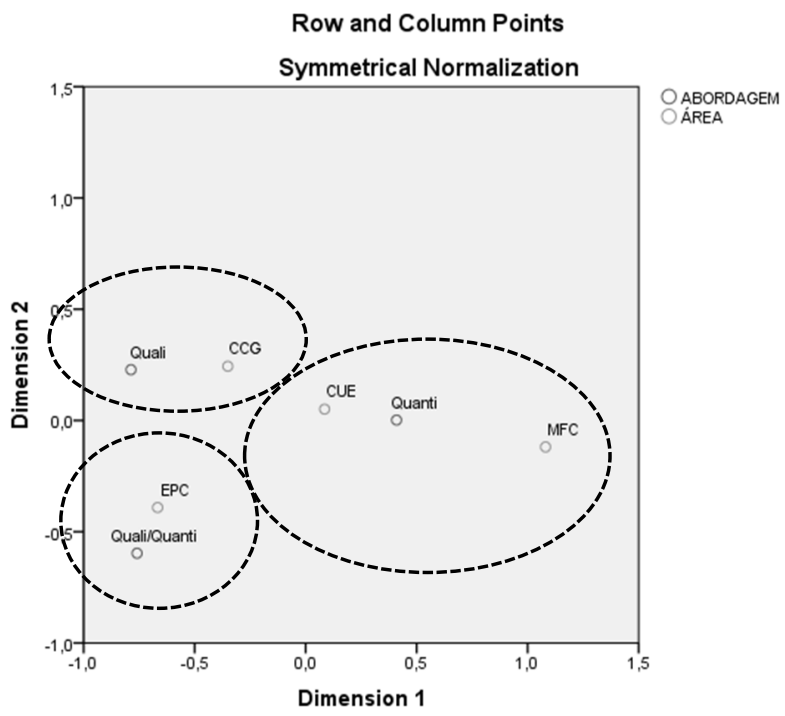

Fonte: Elaborada pelos autores. 
As áreas CUE e MFC estão próximas à abordagem quantitativa, em virtude da associação à tradição de pesquisa positiva. O resultado corrobora com o que foi encontrado por Benetti e Reginato (2007), que destacaram a associação significativa entre a abordagem quantitativa à área de Mercado de Capitais, entre a abordagem qualitativa à área de Temas Emergentes e entre a abordagem mista e à área de Ensino e Pesquisa em Contabilidade.

O estudo de Cosenza et al. (2016) também analisou artigos do ANPCONT, sendo que entre 2007 e 2014 e nas áreas CUE e CCG, encontrou que o congresso possuía tradição de pesquisa baseada em abordagem positiva, com preponderância de métodos quantitativos, com base empírica, mas que vêm cedendo lugar para métodos de estudos de caso e surveys, em que a área CCG mostrava-se com métodos e paradigmas de forma mais distribuída, heterogênea e variada, o que está de acordo com o resultado encontrado pela presente pesquisa.

\subsection{Associação entre áreas temáticas e pesquisa qualitativa}

Para responder ao objetivo de verificar associações entre áreas temáticas, abordagens e instituições foi utilizada a Análise de Correspondência Múltipla (ACM). O teste qui-quadrado feito inicialmente, mostrando que há associação entre as variáveis área, instituição e abordagem, sendo assim, ao nível de significância de $5 \%$, há indícios que apontam à rejeição de $\mathrm{H}_{0}$ de independência das variáveis, ou seja, pode ser aplicada à ACM.

Ao analisar as 20 instituições com mais artigos publicados no evento, percebe-se que as instituições UEM, UFPE, UFRN e UFSC se apresentam associadas à abordagem qualitativa, enquanto que FUCAPE, FURB, UERJ, UFBA, UFC, UFES, UFMG, UFPB, UFPR, UFRJ, UnB, UNISINOS, UPM, USP e USP/RP se apresentam associadas à abordagem quantitativa. A UFU se encontra associada à abordagem qualitativa-quantitativa.

Levando em conta as associações com resultados mais expressivos entre as áreas, instituição e abordagem, a UFES se aproximou mais da área MFC e abordagem quantitativa, a UFRN à CCG e abordagem qualitativa, a UFU à EPC e abordagem qualitativa-quantitativa e a USP à CUE e abordagem quantitativa.

O Quadro 4 apresenta as 20 instituições com maior quantidade de artigos publicados no evento desde a sua criação, dentre as 145 instituições encontradas (considerando somente a instituição do primeiro autor do artigo). Percebe-se que há uma predominância da abordagem quantitativa nos artigos oriundos de quinze instituições (destaque para as sete primeiras posições do ranking).

As três primeiras Universidades também foram destacadas por Matos et al. (2012), que apresentam maior nível de publicação na USP (SP), Fucape (ES) e FURB (SC), instituições nas regiões sudeste e sul com maior produção científica na área (SANTOS; CARLIN, 2012), corroborando a pesquisa de Mendonça Neto, Riccio e Sakata (2009) que aponta as duas primeiras instituições citadas, além do programa conjunto UNB/UFPB/UFPE/UFRN, cujas instituições atualmente possuem o seu próprio Programa de Pós-Graduação na área de Contabilidade. Esses resultados permitem revelar e confirmar o perfil das pesquisas empreendidas nos programas stricto sensu, por ser o evento um primeiro estágio formal e externo no processo de comunicação científica.

Para atingir o objetivo principal do trabalho em analisar a associação entre as metodologias de pesquisa qualitativa utilizadas na área contábil e as áreas temáticas do Congresso ANPCONT, optou-se por utilizar a técnica de Análise de Homogeneidade nos dados tratados anteriormente. Esses dados foram obtidos por meio da análise de conteúdo dos 325 artigos que utilizaram abordagem qualitativa e qualitativa/quantitativa em sua metodologia. 
Pesquisa qualitativa em contabilidade: um panorama de sua evolução no congresso ANPCONT à luz da literatura internacional

\begin{tabular}{|c|c|c|c|}
\hline INSTITUIÇÃ O & ARTIGOS & ÁREA & ABORDAGEM \\
\hline FUCAPE & 105 & MFC & Quantitativa \\
\hline FURB & 85 & CUE & Quantitativa \\
\hline USP & 68 & CUE & Quantitativa \\
\hline UFPB & 44 & MFC & Quantitativa \\
\hline UFPR & 40 & CUE & Quantitativa \\
\hline USP/RP & 40 & CUE & Quantitativa \\
\hline UNISINOS & 37 & CUE & Quantitativa \\
\hline UFMG & 36 & CUE & Quantitativa \\
\hline UFSC & 36 & $\mathrm{CCG}$ & Qualitativa \\
\hline UFC & 34 & CUE & Quantitativa \\
\hline UFU & 32 & EPC & Quali/quanti \\
\hline UPM & 27 & CUE & Quantitativa \\
\hline UFES & 26 & $\mathrm{MFC}$ & Quantitativa \\
\hline UFPE & 22 & $\mathrm{CCG}$ & Qualitativa \\
\hline UFRJ & 21 & CUE & Quantitativa \\
\hline UnB & 21 & CUE & Quantitativa \\
\hline UFBA & 18 & CUE & Quantitativa \\
\hline UERJ & 14 & CUE & Quantitativa \\
\hline UFRN & 12 & $\mathrm{CCG}$ & Qualitativa \\
\hline UEM & 11 & $\mathrm{CCG}$ & Qualitativa \\
\hline
\end{tabular}

Fonte: Dados da Pesquisa.

Foram realizadas ANACOR entre área-estratégia, área-coleta e estratégia-coleta, e os resultados do teste qui-quadrado confirmam que as variáveis podem ser analisadas conjuntamente com o uso de HOMALS, já que houve indícios de rejeição de $\mathrm{H}_{0}$ de independência entre elas.

As análises de correspondência entre as variáveis mostraram ainda que com a investigação apenas dos artigos com abordagem qualitativa, a área com maior número de artigos foi a CCG, seguida de CUE, EPC e MFC, e a estratégia predominante é a documental, conforme os achados de Theóphilo e Iudícibus (2009), seguida de estudo de caso e pesquisa bibliográfica, como mostra a Tabela 3. Cabe destacar que se verifica uma correspondência entre a área de CCG e a estratégia de estudo de caso, enquanto as demais áreas se relacionam com a estratégia de pesquisa documental.

Tabela 3 - Tabela de correspondência entre área e estratégia

\begin{tabular}{lrrrrrrrr}
\hline ÁREA & \multicolumn{1}{c}{ ESTRATÉGIA } & \multicolumn{1}{c}{} \\
\cline { 2 - 9 } & EC & ET & GT & MH & PA & BI & DO & Active Margin \\
\hline CCG & 77 & 2 & 0 & 1 & 2 & 18 & 20 & 120 \\
CUE & 17 & 2 & 1 & 1 & 1 & 10 & 77 & 109 \\
MFC & 1 & 0 & 0 & 1 & 0 & 1 & 6 & 9 \\
EPC & 13 & 3 & 0 & 2 & 0 & 24 & 45 & 87 \\
Active Margin & 108 & 7 & 1 & 5 & 3 & 53 & 148 & 325 \\
\hline
\end{tabular}

Fonte: Dados da Pesquisa.

*Abreviaturas utilizadas: EC=Estudo de caso, ET=Etnografia, GT=Grounded Theory, MH=Método Histórico, PA=Pesquisa Ação, BI=Bibliográfica e DO=Documental.

Quanto à associação entre áreas e coletas de dados evidenciados na Tabela 4, houve uma predominância de documentos isoladamente como técnica de coleta em todas as áreas, seguindose as técnicas combinadas documentos + entrevista e documentos + entrevista + observação, conforme apontado por Lee e Humphrey (2006) como as mais utilizadas na área contábil. A área de CCG possui maior frequência de técnicas combinadas com documentos em comparação às demais áreas, fato que confirma os achados de Modell (2010) e Paula et al. (2012). 
Rodrigo Carlos Marques Pereira, Fabrícia de Farias da Silva Constantino, Fernanda Filgueiras Sauerbronn, Marcelo Alvaro da Silva Macedo

Tabela 4 - Tabela de correspondência entre área e coleta de dados

\begin{tabular}{cccccc}
\hline \multirow{2}{*}{ COLETA } & \multicolumn{5}{c}{ ÁREA } \\
\cline { 2 - 5 } & CCG & CUE & MFC & EPC & Active Margin \\
\hline Ent & 2 & 5 & 0 & 4 & 11 \\
Obs & 0 & 0 & 0 & 0 & 0 \\
Doc & 48 & 91 & 8 & 72 & 3 \\
MVi & 0 & 0 & 0 & 3 & 0 \\
MCD & 0 & 0 & 0 & 0 & 0 \\
GF & 0 & 0 & 0 & 0 & 54 \\
Doc + Ent & 41 & 6 & 1 & 6 & 22 \\
Doc + Ent + GF & 2 & 1 & 0 & 0 & 2 \\
Doc + Ent + Obs & 19 & 2 & 0 & 1 & 1 \\
Doc + Ent + Obs + GF & 2 & 0 & 0 & 0 & 1 \\
Doc + MCD & 1 & 0 & 0 & 0 & 1 \\
Doc + Obs & 3 & 2 & 0 & 1 & 2 \\
Doc + Obs + GF & 0 & 1 & 0 & 0 & 325 \\
Ent + GF & 0 & 1 & 0 & 0 & 0 \\
Ent + Obs & 2 & 0 & 0 & 87 & 1 \\
Active Margin & 120 & 109 & 9 & 0 & 2 \\
\hline
\end{tabular}

Fonte: Dados da Pesquisa.

*Abreviaturas utilizadas: Ent=Entrevista, Obs=Observação, Doc=Documentos, MVi=Métodos visuais, $\mathrm{MCD}=$ Métodos de controle de dados, $\mathrm{GF}=$ Grupos focais.

Quanto à associação entre estratégias e coleta de dados, na Tabela 5 o método de coleta com uso de Documentos se destacou, apresentando 219 observações, estando presente em quase todas as estratégias, exceto Etnografia e Grounded Theory. Em segundo lugar está "Documento + Entrevista" com 54 casos, em que $87 \%$ estão presentes na estratégia de Estudo de Caso. Sobre as estratégias, a que apresenta maior número de observações é a Documental.

Tabela 5 - Tabela de correspondência entre estratégias e coleta de dados

\begin{tabular}{ccccccccc}
\hline COLETA & \multicolumn{1}{c}{ ESTRATÉGIA } \\
\cline { 2 - 8 } & EC & ET & GT & MH & PA & BI & DO & Active Margin \\
\hline Ent & 8 & 2 & 0 & 0 & 0 & 0 & 1 & 11 \\
Obs & 0 & 0 & 0 & 0 & 0 & 0 & 0 & 0 \\
Doc & 18 & 0 & 0 & 4 & 2 & 53 & 142 & 219 \\
MVi & 0 & 1 & 0 & 0 & 0 & 0 & 2 & 3 \\
MCD & 0 & 0 & 0 & 0 & 0 & 0 & 0 & 0 \\
GF & 0 & 0 & 0 & 0 & 0 & 0 & 0 & 0 \\
Doc + Ent & 47 & 2 & 1 & 1 & 0 & 0 & 3 & 54 \\
Doc + Ent + GF & 3 & 0 & 0 & 0 & 0 & 0 & 0 & 3 \\
Doc + Ent + Obs & 21 & 1 & 0 & 0 & 0 & 0 & 0 & 22 \\
Doc + Ent + Obs + GF & 2 & 0 & 0 & 0 & 0 & 0 & 0 & 2 \\
Doc + MCD & 1 & 0 & 0 & 0 & 0 & 0 & 0 & 1 \\
Doc + Obs & 5 & 0 & 0 & 0 & 1 & 0 & 0 & 6 \\
Doc + Obs + GF & 1 & 0 & 0 & 0 & 0 & 0 & 0 & 1 \\
Ent + GF & 0 & 1 & 0 & 0 & 0 & 0 & 0 & 1 \\
Ent + Obs & 2 & 0 & 0 & 0 & 0 & 0 & 0 & 2 \\
Active Margin & 108 & 7 & 1 & 5 & 3 & 53 & 148 & 325 \\
\hline
\end{tabular}

*Abreviaturas utilizadas: EC=Estudo de caso, ET=Etnografia, GT=Grounded Theory, MH=Método Histórico, PA=Pesquisa Ação, BI=Bibliográfica, DO=Documental; Ent=Entrevista, Obs=Observação, Doc=Documentos, $\mathrm{MVi}=$ Métodos visuais, $\mathrm{MCD}=$ Métodos de controle de dados, $\mathrm{GF}=\mathrm{Grupos}$ focais.

Fonte: Dados da Pesquisa.

Destaca-se a associação entre a estratégia estudo de caso com as coletas combinadas: documentos + entrevista, documentos + observação, documentos + entrevista + grupo focal, documentos + entrevista + observação, documentos + método de controle de dados, documentos + observação + grupo focal, documentos + entrevista + observação + grupo focal. As estratégias: documental, bibliográfica, método histórico e pesquisa ação estão associadas com a técnica de 
coleta por meio de documentos (seguindo a ordem crescente de associação). etnografia está associada aos métodos visuais. O método de coleta entrevista com grupo focal não está associado a nenhuma estratégia.

Os resultados corroboram o argumento de Bowen (2009), no qual a análise de documentos é frequentemente usada em combinação com outros métodos de pesquisa qualitativa. Segundo este autor, espera-se que o pesquisador qualitativo se baseie em múltiplas, pelo menos duas, fontes de evidência, buscando convergência e corroboração por meio do uso de diferentes fontes de dados e métodos, tornando o processo de análise tão rigoroso e transparente quanto possível.

Ao verificar a associação entre as variáveis área, estratégia e coleta em conjunto, foi utilizada a técnica multivariada HOMALS. A representação gráfica das associações entre as variáveis é ilustrada pela Figura 2, em que a área CCG está associada à estratégia Estudo de caso, utilizando as técnicas combinadas com documentos como métodos de coleta de dados; as áreas EPC, CUE e MFC encontram-se associadas às pesquisas documental, bibliográfica e método histórico, com documentos como método de coleta de dados. Destaca-se que não foram encontradas associações claras entre as estratégias grounded theory, pesquisa ação e etnografia com as áreas e métodos de coleta. E não houve associação entre os métodos de coleta entrevista + grupo focal, métodos visuais, entrevista às áreas e às estratégias.

\section{Figura 2 - Mapa perceptual para Área, Estratégia e Coleta}

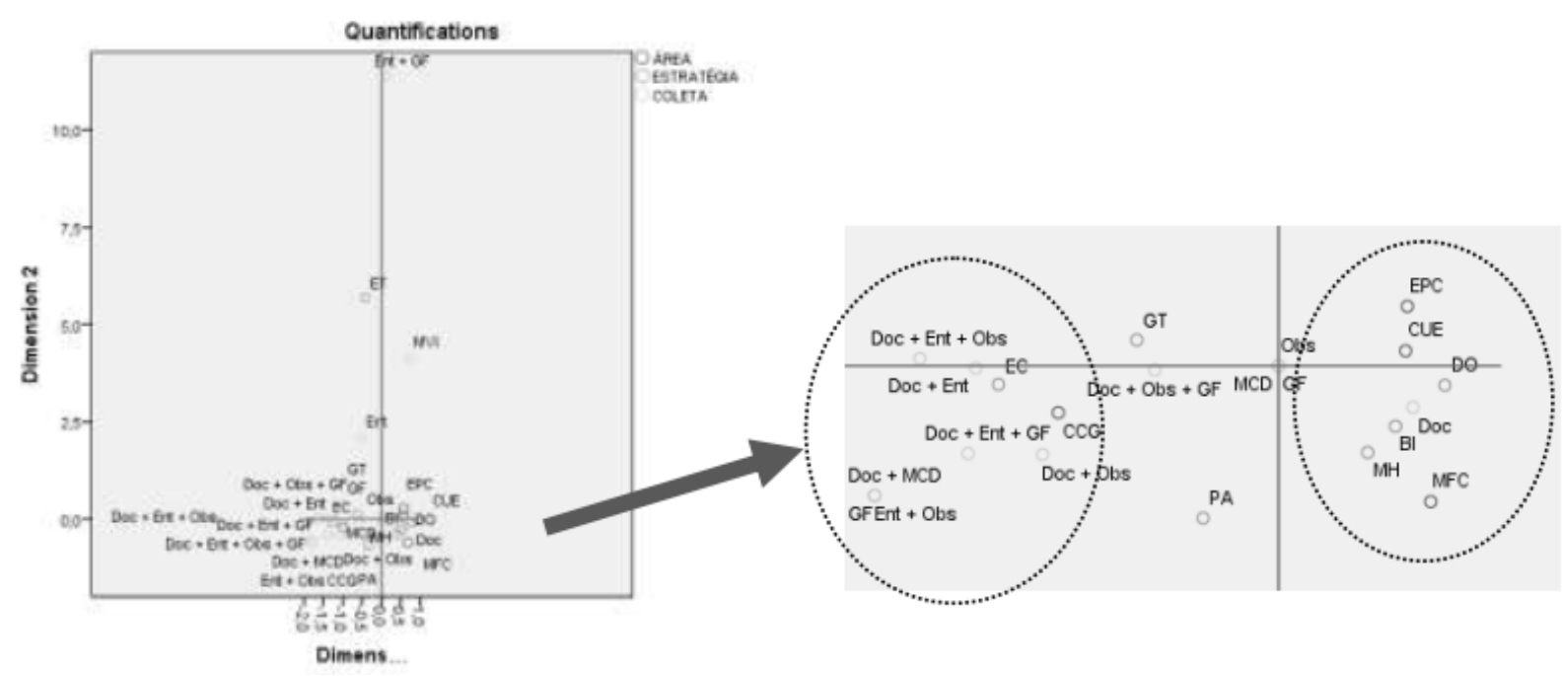

Fonte: Dados da pesquisa.

\subsection{Lacuna entre a pesquisa qualitativa contábil nacional e internacional}

Por fim, ao analisar estes artigos com relação à abordagem científica da pesquisa contábil e segundo a interpretação dos pesquisadores, percebeu-se que ao longo dos dez anos do evento houve somente oito trabalhos com abordagem normativa, com concentração de seis no primeiro ano do evento em 2007. Em sua pesquisa sobre as dissertações dos programas de pós-graduação em ciências contábeis, Spessatto e Bezerra (2008) encontraram predominância da utilização da abordagem positiva no período analisado, corroborando também com a pesquisa de Mendonça Neto, Riccio e Sakata (2009) em trabalhos sobre contabilidade apresentados no ENANPAD. Assim, depreende-se da análise que a abordagem positiva permanece como mainstream nas pesquisas da área contábil, apontando para a mudança de perspectiva teórica, que no início tinha um caráter mais normativo por apontar como deveriam ser as práticas contábeis, passando então para sua descrição e análise. 
Assim como as afirmativas de Martins (2005), se mantém a existência de pouco lugar para trabalhos acadêmicos que não estejam fundamentados em algum nível de empirismo e calcados na lógica do positivismo. Esse cenário traz implicações quanto ao potencial de aparecerem os artigos que criam ideias e sugerem alternativas. Segundo Vaivio (2008), a apresentação de novas ideias fora do mainstream sempre requer uma elevada habilidade de articulação epistemológica e metodológica necessária às pesquisas qualitativas. O cenário revelado pelo presente estudo mostra que esse é um caminho ainda pouco explorado no Brasil.

Com base no mapeamento descrito por esta pesquisa, percebe-se que, por mais que haja uma diversidade de possibilidades de estratégias e técnicas de coletas de dados qualitativos (RICHARDSON, 1999; DENZIN; LINCONL, 2006; VERGARA, 2009; HOQUE et al., 2017) o número de pesquisas que se utilizam de diferentes abordagens metodológicas ainda é pequeno em relação ao total de trabalhos, mostrando uma lacuna a ser explorada pelo meio acadêmico nacional.

\section{Considerações Finais}

A análise dos dados apontou que, nos primeiros dez anos de existência, o Congresso ANPCONT apresentou 949 artigos de diferentes instituições, que buscou disseminar os estudos contábeis por meio de quatro áreas temáticas com perfis de abordagens, estratégias de pesquisa e técnicas de coleta de dados diferenciados conforme as características da produção científica de cada área.

As metodologias empregadas nesses artigos foram classificadas de acordo com autores reconhecidos na área de pesquisa científica contábil, e cada artigo foi analisado com a técnica de análise de conteúdo nas seções que abordassem aspectos metodológicos referentes à pesquisa. Cabe ressaltar que, na maioria dos artigos, a informação relevante para categorização estava descrita de forma explícita, porém em alguns casos o julgamento dos pesquisadores foi necessário para categorizá-los.

Constatou-se que, conforme os achados de Rodrigues et al. (2011), se mantém na área uma tendência de aumento dos trabalhos com abordagem qualitativa, mesmo diante do predomínio quantitativo. Ao analisar visualmente o mapa perceptual na Figura 1 quanto à associação de áreas temáticas e abordagem de pesquisa, verificou-se que as áreas temáticas CUE e MFC permanecem em grande parte associadas à abordagem quantitativa de pesquisa, já CCG à abordagem qualitativa e EPC à abordagem conjunta qualitativa/quantitativa, por estarem mais próximas. Quanto às estratégias e técnicas de coleta de dados, adentrando apenas os artigos qualitativos, os resultados apontam que a área CCG está associada à estratégia estudo de caso, utilizando outras técnicas de coleta combinadas com documentos. Já as áreas EPC, CUE e MFC encontram-se associadas às pesquisas documental e bibliográfica, em grande parte com a coleta de dados por meio de documentos. Cabe destacar também que os resultados apontam que a análise de documentos vem sendo usada em combinação com outros métodos de coleta de dados, com triangulação de fontes de evidência.

Adicionalmente, o resultado do presente estudo confirma a característica na qual a contabilidade financeira estaria mais associada aos métodos quantitativos, enquanto a contabilidade gerencial aos métodos qualitativos. Entretanto, cabe observar que, aproximadamente $32 \%$ das pesquisas em CUE tiveram trabalhos classificados como qualitativos, sendo a coleta de dados documental com consulta a notas explicativas e às análises nas demonstrações financeiras das empresas, mesmo que em associação às análises somente qualitativas ou mistas (quali/quanti). Por outro lado, nas áreas com maior volume de produção qualitativa (CCG e EPC), observa-se que a produção ainda está atrelada aos métodos qualitativos mais tradicionalmente alinhados a um paradigma funcionalista em contabilidade, conforme apontado por Hoque et al. (2017) - como o estudo de caso -, em detrimento de estratégias alternativas quase inexistentes nas pesquisas nacionais como a etnografia, a grounded theory, a historiografia e a pesquisa ação. 
De certo, a partir da análise dos resultados é possível concluir também que ainda há na área contábil um grande potencial de desenvolvimento para melhor aproveitar a ampla variedade de práticas de pesquisa qualitativas (HOQUE et al., 2017), que são oferecidas por outras estratégias de pesquisa construídas pelas ciências sociais nas últimas décadas (DENZIN; LINCONL, 2006), com objetivo de aprofundar e compreender melhor os fenômenos. Certamente, o crescimento da pesquisa qualitativa se dará em função do interesse dos pesquisadores em observarem o fenômeno contábil com certa amplitude e complexidade, que demandem um desenho de pesquisa qualitativa (LEE; HUMPHREY, 2006).

Nesse sentido, é possível afirmar a existência de espaço para o desenvolvimento de pesquisas qualitativas como as já indicadas na literatura internacional de contabilidade (ver HOQUE et al., 2017), e que ainda são reduzidas em algumas áreas de submissão do evento ANPCONT. Ao cotejar os resultados da pesquisa a essa literatura qualitativa internacional, depreende-se que há espaço para: (i) ampliar a pesquisa qualitativa "de gabinete" (desk based) ao associar a pesquisa documental com a análise de discurso, de narrativas ou métodos visuais, ao invés da simples análise de conteúdo; (ii) propiciar o engajamento dos pesquisadores com a prática da contabilidade por meio da pesquisa ação, da investigação apreciativa, da pesquisa intervencionista e da pesquisa histórica, em associação aos estudos de casos múltiplos ou únicos; (iii) aproximar os pesquisadores dos praticantes da contabilidade por meio das diversas formas de etnografia e das formas de coleta "face a face" como entrevistas, grupos focais e das formas de observação participante e não-participante.

Os resultados também revelam serem importantes para os contornos da pesquisa qualitativa no Brasil, em função do volume, os estudos advindos dos programas das seguintes instituições: UFSC, UFPE, UFRN, UEM e UFU. Esse resultado indica a possibilidade de se compreenderem aspectos que expliquem o volume de trabalhos qualitativos, como por exemplo, os aspectos relacionados às disciplinas lecionadas ou à composição (e trajetória) do corpo docente dos programas.

Por fim, cabe destacar que este estudo não teve a pretensão de generalizar as características da produção científica a outros eventos ou periódicos, mas sim apontar os caminhos percorridos pela área, em um importante espaço na primeira etapa de comunicação científica formal, e seus desdobramentos em um amplo recorte temporal. Sendo assim, sugere-se adicionalmente como estudos futuros a análise de outros eventos, e principalmente, de revistas, para comparação de resultados, de forma a ampliar a compreensão dos avanços ou limitações às pesquisas qualitativas em contabilidade no Brasil.

\section{Referências}

ANNISETTE, M., COOPER, C., GENDRON, Y. After 25 years, how should we proceed? Critical Perspectives on Accounting, v. 43, p. 1-4, 2017. Disponível em: <http://dx.doi.org/10.1016/j.cpa.2017.02.003>. Acesso em: 20 abr. 2017.

ASSOCIAÇÃO NACIONAL DE PROGRAMAS DE PÓS-GRADUAÇÃO EM CIÊNCIAS CONTÁBEIS (ANPCONT). Congresso ANPCONT. Disponível em: <http://www.anpcont.org.br/congresso2019.php>. Acesso em: 05 mai. 2017.

BAKER, C. R.; BETTNER, M. S. Interpretive and critical research in accounting: a commentary on its absence from mainstream accounting research. Critical Perspectives on Accounting, v. 8, n. 4, p. 293-310, 1997. Disponível em: 〈https://doi.org/10.1006/cpac.1996.0116>. Acesso em: 16 jun. 2018.

BARDIN, L. Análise do discurso. Lisboa: Edições, v. 70, 1977. 
BENETTI, C., REGINATO, L. Análise dos trabalhos apresentados nos $5^{\circ}$ e $6^{\circ}$ congressos USP de controladoria e contabilidade quanto às técnicas e aos métodos qualitativos. In: Encontro de Ensino e Pesquisa em Administração e Contabilidade, 2007, Recife. Anais ... EnEPQ, 2007.

BOWEN, G. A. Document analysis as a qualitative research method. Qualitative Research Journal, v. 9, n. 2, p. 27-40, 2009. Disponível em: 〈https://doi.org/10.3316/QRJ0902027>. Acesso em: 16 jun. 2017.

COSEnZA, J. P., PAUlA, M. M., LAURENCEL, L. C., BARRETO, P. S. Análise das características e similaridades presentes na produção científica dos congressos ANPCONT 20072014. Revista Contemporânea de Contabilidade, v. 13, n. 28, p. 19-56, 2016. Disponível em: <https://doi.org/10.5007/2175-8069.2016v13n28p19>. Acesso em: 05 mai. 2017.

CRESWELL, J. W. Mixed-method research: Introduction and application. Handbook of Educational Policy, p. 455-472, 1999. Disponível em: <https://doi.org/10.1016/B978012174698-8/50045-X>. Acesso em: 15 abr. 2017.

DENZIN, N. K., GIARDINA, M. D. Qualitative inquiry and the conservative challenge. Walnut Creek: Left Coast Press, 2006.

DENZIN, N. K., LINCOLN, Y. S. O planejamento da pesquisa qualitativa: teoria e abordagens. Porto Alegre: Artmed, 2006.

DIAS FILHO, J. M., MACHADO, L. H. B. Abordagens da pesquisa em contabilidade. Teoria avançada da contabilidade. São Paulo: Atlas, 2004.

DOWD, K. Qualitative Dimensions in Finance and Risk Management Research. In: Humphrey, L. The Real Life Guide to Accounting Research: A Behind-the-Scenes View of Using Qualitative Research Methods, 2004. cap. 30, pp. 509-523. Disponível em: <https://doi.org/10.1016/B978-008043972-3/50032-3>. Acesso em: 10 mai. 2017.

FÁVERO, L. P., BELFIORE, P., SILVA, F. D., CHAN, B. L. Análise de dados: modelagem multivariada para tomada de decisões. São Paulo: Elsevier, 2009.

FREZATTI, F., NASCIMENTO, A. R., JUNQUEIRA, E. Desenvolvimento da pesquisa em contabilidade gerencial: as restrições da abordagem monoparadigmática de Zimmerman. Revista Contabilidade e Finanças, v. 20, n. 6, 2009. Disponível em: <https://doi.org/10.1590/S1519$70772009000100002>$. Acesso em: 05 mai. 2017.

HOQUE, Z., PARKER, L. D., COVALESKI, M. A., HAYNES, K. The routledge companion to qualitative accounting research methods. New York: Routledge, 2017.

IUDÍCIBUS, S., BEUREN, I. M., SANTOS, V. Ensino da Teoria da Contabilidade nos Programas de Pós-graduação de Ciências Contábeis do Brasil. Revista Universo Contábil, v. 12, n. 4, p. 0629, 2016. Disponível em: <https://doi.org/ 10.4270/RUC.2016425>. Acesso em: 05 mai. 2017.

KUHN, T. S. The structure of scientific revolutions. Chicago: The University of Chicago Press, 1962. 
LAVILLE, C., DIONNE, J. A construção do saber: manual de metodologia da pesquisa em ciências humanas. Artmed; UFMG, 1999.

LEE, B., HUMPHREY, C. More than a numbers game: qualitative research in accounting. Management Decision, v. 44, n.2, p. 180-197, 2006. Disponível em: <https://doi.org/10.1108/00251740610650184>. Acesso em: 01 dez. 2016.

LOURENÇO, R. L., SAUERBRONN, F. F. Revistando possibilidades epistemológicas em contabilidade gerencial: em busca de contribuições de abordagens interpretativas e críticas no Brasil. Revista Contemporânea de Contabilidade, v.13, n. 28, p. 99-122, 2016. Disponível em: <https://doi.org/10.5007/2175-8069.2016v13n28p99>. Acesso em: 01 out. 2016.

MACHADO, E. A., CRUZ, A. P. C. D., NOGUEIRA, D. R., MARTINS, G. D. A. Contorno metodológico da produção científica sobre ensino e pesquisa em contabilidade: um olhar epistemológico. In: Congresso ANPCONT, V, 2011, Vitória. Anais ... ANPCONT, 2011.

MARTINS, E. Editorial: normativismo e/ou positivismo em contabilidade: qual o futuro? Revista Contabilidade \& Finanças, v. 16, n. 39, p. 3-3, 2005. Disponível em: <https://doi.org/10.1590/S1519-70772005000300001>. Acesso em: 15 mar. 2017.

MARTINS, G. D. A., THEÓPHILO, C. R. Metodologia da investigação científica. São Paulo: Atlas, 2009.

MATOS, E. B. S., NIYAMA, J. K., ARAÚJO NETO, L. M.; MENDONÇA MARQUES, M. Congresso ANPCONT: análise bibliométrica descritiva e avaliativa dos artigos publicados de 2007 a 2011. Enfoque: Reflexão Contábil, v. 31, n.3, p.73-88, 2012. Disponível em: < https://doi.org/10.4025/enfoque.v31i3.16946

MENDONÇA NETO, O. R. D., RICCIO, E. L.; SAKATA, M. C. G. Dez anos de pesquisa contábil no Brasil: análise dos trabalhos apresentados nos ENANPADs de 1996 a 2005. Revista de Administração de Empresas, v. 49, n.1, p.62-73, 2009. Disponível em: <https://doi.org/10.1590/S0034-75902009000100008>. Acesso em: 01 abr. 2017.

MODELL, S. Bridging the paradigm divide in management accounting research: The role of mixed methods approaches. Management Accounting Research, v.21, n.2, p.124-129, 2010. Disponível em: <https://doi.org/10.1016/j.mar.2010.02.005>. Acesso em: 30 mar. 2017.

NASCIMENTO, A. R., JUNQUEIRA, E.; MARTINS, G. A. A pesquisa acadêmica em contabilidade gerencial no Brasil: análise e reflexões sobre teorias, metodologias e paradigmas. Revista de Administração Contemporânea, v.14, n. 6, p. 1113-1133, 2010. Disponível em: <https://doi.org/10.1590/S1415-65552010000700008>. Acesso em: 10 abr. 2017.

PARKER, L. D. Interpreting interpretive accounting research. Critical Perspectives on Accounting, v. 19, n. 6, p. 909-914, 2008. Disponível em: <https://doi.org/10.1016/j.cpa.2007.03.013>. Acesso em: 07 abr. 2017.

PAUlA, M., SILVA, A., VIEIRA, J.; COUTINHO, A. Diálogo Científico nos Congressos Anpcont: Diversidade Inovadora ou Isomorfismo Institucionalizado? Contabilidade, Gestão e Governança, v.15, n. 3, 2012. 
RAUPP, F. M.; BEUREN, I. M. Metodologia da Pesquisa Aplicável às Ciências Sociais. In: BEUREN, I. M. Como Elaborar Trabalhos Monográficos em Contabilidade: Teoria e Prática. São Paulo: Atlas, 2003, pp. 76-97.

RICHARDSON, R. J. Pesquisa Social: métodos e técnicas. São Paulo, Atlas, 1999.

RODRIGUES, J. M., BORGES, E. F., SILVA, C. A. T.; SANTANA, C. M. Paradigmas na pesquisa contábil no brasil: um estudo epistemológico sobre a evolução nos trabalhos de programas de pós-graduação em ciências contábeis. ConTexto, v.11, n. 19, pp. 21-30, 2011.

SANTOS, P. R. P.; CARLIN, D. O. Análise da produção científica do Congresso ANPCONT: um estudo bibliométrico sobre o processo de convergência aos padrões internacionais de Contabilidade. ConTexto, v. 12, n. 22, p. 131-144, 2012.

SCAPENS, R.W. Doing case study research. In: HUMPHREY, C.; LEE, B. (Eds), The Real Life Guide to Accounting Research: A Behind the Scenes View of Using Qualitative Research Methods. Oxford: Elsevier, 2004, pp. 257-80.

SPESSATTO, G.; BEZERRA, F. A. Utilização das abordagens positiva e normativas nas pesquisas em contabilidade. In: XV Congresso Brasileiro de Custos - Curitiba/PR, Brasil, 12 a 14 de novembro de 2008. Anais ..., 2008.20 Disponível em: <https://anaiscbc.emnuvens.com.br/anais/article/download/1193/1193>. Acesso em: 07 abr. 2017.

THEÓPHILO, C. R.; IUDÍCIBUS, S. Uma análise crítico-epistemológica da produção científica em contabilidade no Brasil. Contabilidade, Gestão e Governança, v. 8, n. 2, 2009.

VAIVIO, J. Qualitative management accounting research: rationale, pitfalls and potential. Qualitative Research in Accounting \& Management, v. 5, n. 1, p. 64-86, 2008. Disponível em: <https://doi.org/10.1108/11766090810856787>. Acesso em: 10 jun. 2017.

VERGARA, S. C. Projetos e relatórios de pesquisa em administração. São Paulo: Atlas, 2009.

VIEIRA, M. M. Por uma (boa) pesquisa qualitativa em administração. In: VIEIRA, M. M. F.; ZOUAIN, D. M. Pesquisa qualitativa em administração. Rio de Janeiro: FGV, 2004, pp.13-28. (2004).

WATTS, R.; ZIMMERMAN, J. Positive Theory of Accounting. New York: Prentice-Hall, 1986. 